\title{
Helping Family Physicians Keep Up to Date: A Next Step in the Pursuit of Mastery
}

\author{
Martin A. Quan, MD and Warren P. Newton, MD
}

The American Board of Family Medicine (ABFM) is exploring the development of an ABFM Journal Club as a part of its continuing certification portfolio. To benchmark this effort, we reviewed the journal article activities of 8 other American Board of Medical Specialties boards. This paper identifies the principles that will drive the design of the optional ABFM lifelong learning and self-assessment activity. Articles for consideration will be identified through an explicit structured search process. A National Journal Club Committee will choose the top 100 articles based on methodologic rigor, generalizability and relevance to family medicine, and potential to change practice. A postactivity assessment instrument will require mastery learning of new clinical findings and support deeper learning, with the goal of supporting personal physicians in keeping up to date and informing shared decision-making. ( $\mathrm{J}$ Am Board Fam Med 2020;33:S24-S27.)

Keywords: Certification, Continuing Medical Education, Family Medicine, Family Physicians, Specialty Boards, Training Support

The American Board of Medical Specialties (ABMS) Continuing Board Certification: Vision Commission Final Report calls for a new approach to board certification, one that combines summative judgments with activities that support learning. In this context, the American Board of Family Medicine (ABFM) is exploring the development of an ABFM Journal Club as a part of its certification portfolio.

The first journal club was organized by Sir William Osler while at McGill University in Montreal in $1875^{1}$ and who is quoted as saying "It is astonishing with how little reading a doctor can practice medicine, but it is not astonishing how badly he may do it." ${ }^{2}$ Since the days of Osler, keeping current with the medical literature has been greatly complicated by the rapidly enlarging volume of the published peer-reviewed medical

This article was externally peer reviewed.

Submitted 20 April 2020; revised 17 May 2020; accepted 19 May 2020.

From the American Board of Family Medicine, Lexington, KY (WN, MQ).

Funding: None.

Conflicts of interest: Dr. Newton and Dr. Quan are employed by the ABFM.

Corresponding author: Martin A. Quan, MD, University of California Los Angeles David Geffen School of Medicine, 10833 Le Conte Avenue, Los Angeles, CA 90095 (E-mail: mquan@mednet.ucla.edu). literature, with an estimated 10,000 new studies being added each month. ${ }^{3}$ Not surprisingly, in 2004, Alper and associates ${ }^{4}$ calculated that a physician would require nearly 630 hours a month just to keep up with the primary care literature, a number that would be substantially higher today.

To help meet this challenge, a growing number of clinicians have turned to subscription-based journal club-like periodicals, such as the ACP Journal Club and Journal Watch (for which more than 300,000 users are willing to pay up to $\$ 199$ a year) as well as Evidence-Based Medicine (EMB) pointof-care resources, such as Essential Evidence Plus, DynaMed, and UpToDate. In parallel, starting with the American Board of Obstetrics and Gynecology (ABOG), a number of other ABMS boards have developed and integrated journal article-based activities into their continuing certification programs. Following the examples of other boards, ABFM hopes to provide its diplomates with access to practice-changing articles, in full text rather than predigested summaries, as a routine part of its board certification portfolio, and with assessments to engage diplomates in judging the validity, value, and relevance of the article reviewed.

To benchmark design features for a future ABFM activity, we explored what other boards are doing to build current journal articles into their portfolio. 


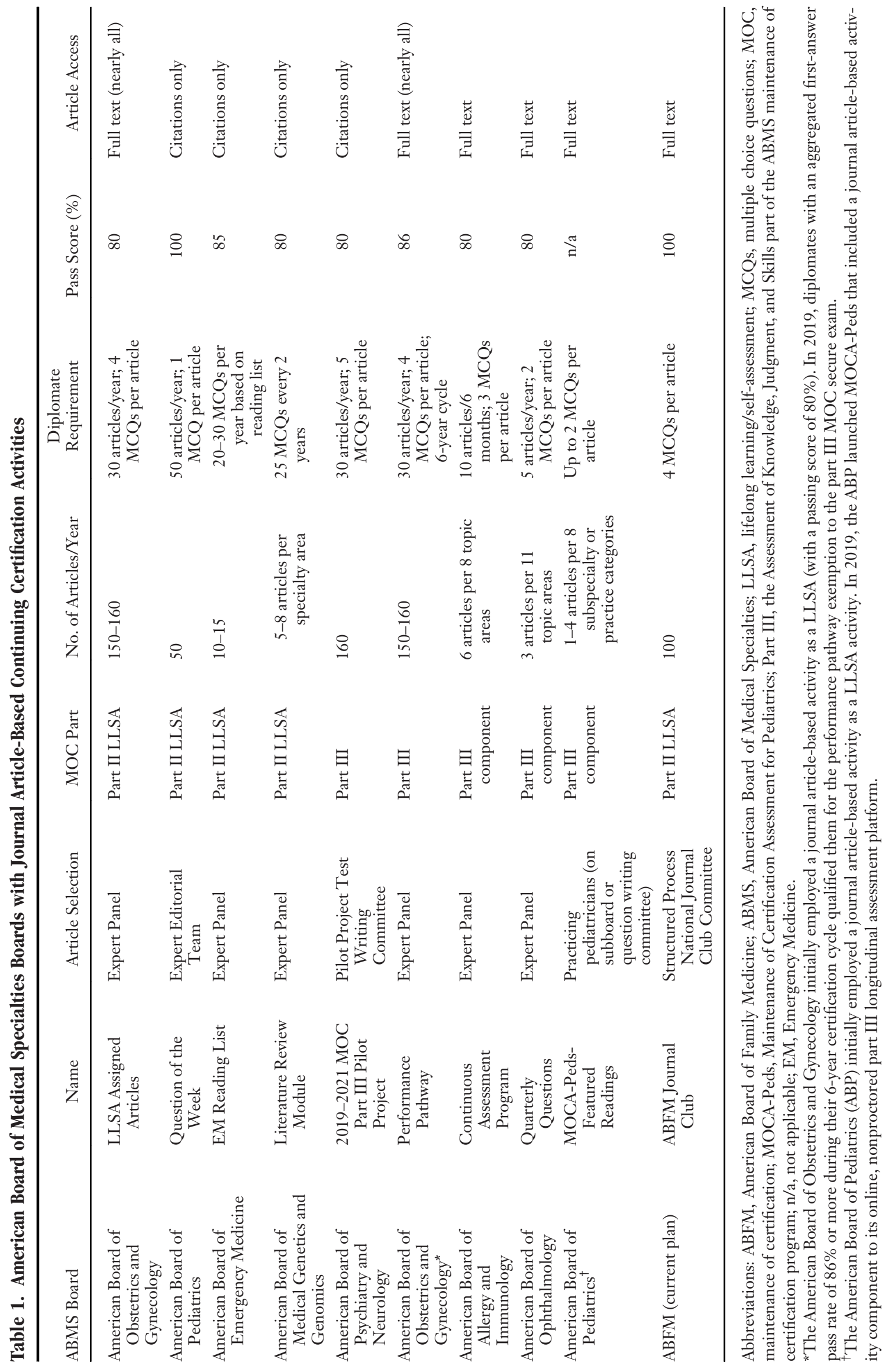

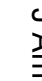

일

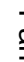

용

蛋

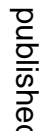

क

.

N

产

N

西

ิㅡㅇ

$\overrightarrow{0}$

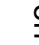

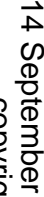

Nㅗㅇ

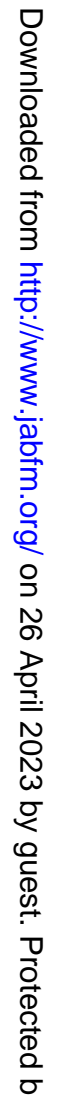


Table 1 depicts what is available on their web sites, supplemented by conversations with key staff.

No less than 7 ABMS boards currently include a journal article-based activity in at least 1 of the 4 parts of their maintenance of certification (MOC) programs, with 2 of them including it in 2 of the parts. Four of them, the ABOG, the American Board of Pediatrics (ABP), the American Board of Emergency Medicine (ABEM), and the American Board of Medical Genetics and Genomics (ABMGG) offer article-based self-assessment activities as a part II lifelong learning/self-assessment (LLSA) component of their continuous certification programs designed to help their diplomates acquire the latest evidence for use in their clinical practices. Two ABMS boards, the American Board of Psychiatry and Neurology $(\mathrm{ABPN})$ and the American Board of Allergy and Immunology (ABAI), are currently engaged in pilot projects evaluating the utility of a longitudinal journal article-based assessment activity as a possible alternative to a part III proctored, high-stakes summative examination. Moreover, the ABOG, following completion of a pilot looking at the utility of its article-based LLSA as a part III alternative, now awards diplomates an exemption to its part III highstakes examination if they achieve a predefined high level of proficiency of performance during MOC cycle years 1 through 5 on its LLSA journal activity. Finally, the American Board of Ophthalmology $(\mathrm{ABOp})$ now includes an article-based activity as 1 of 2 components of its part III longitudinal knowledge assessment activity, and the $\mathrm{ABP}$ incorporates use of articles/practice guidelines into its Maintenance of Certification Assessment for Pediatrics (MOCAPeds) activity, which is the ABP's online, nonproctored part III assessment platform.

What are the implications for a future $A B F M$ Journal Club? These services have proven very popular for diplomates across a wide range of specialties and are viewed as a valued service by their ABMS boards. A core function of specialty boards is the curation of knowledge and prioritization of what is important in their respective disciplines. This function of boards is particularly important as physicians attempt to navigate a mighty river of new clinical evidence-and this is particularly important for family medicine, the quintessential generalist discipline.

How should articles be chosen? Most boards rely on committees comprised of experts-members of boards, typically generalists and specialist leaders of their clinical disciplines-who nominate empirical articles, meta-analyses, and practice guidelines deemed important and relevant to their specialty. As we have learned from the formal study of clinical reviews, however, explicit and structured searches with a filter of the methodological validity appropriate to the clinical question provide appropriate rigor. Furthermore, given that new clinical research is often exploratory or not ready for use in general clinical practice, ${ }^{5}$ it will be important that the $A B F M$ process include a filter of relevance to the practice of family physicians. Finally, following the important distinction between Patient-Oriented Evidence that Matters (POEMS) and DiseaseOriented Evidence (DOE), ${ }^{6}$ journal clubs should prioritize evidence with the potential to change practice-for example, clinical practices that family physicians should adopt, those they should stop doing, as per "Choosing Wisely," and welldesigned landmark studies like the SPRINT trial ${ }^{8}$ whose implications are controversial but that family physicians ought to know about.

How much effort should we ask of family physicians? All other boards require their diplomates to read the full articles; ABOG, with the most experience, asks diplomates to review 30 articles a year, whereas others ask for same or fewer. At present, the ABFM plans for its activity to be an optional lifelong learning/self-assessment activity. Although diplomates will be provided access to all the articles in the portfolio, diplomates will be limited to earning up to a maximum of 10 certification points $(0.5$ point per article) per year by reading 20 articles (self-selected for relevance) and successfully completing the postactivity assessment.

The ABFM Journal Club will emphasize keeping up to date and honing skills of critically appraising sources of information. As currently planned, diplomates will be provided full-text access to the top 100 articles (selected by our specialty for the specialty based on methodologic rigor, clinical relevance for family physicians, and impact on practice) published in the preceding year, followed by a postactivity assessment activity grounded in mastery learning. ${ }^{9}$ The top 100 list will be selected from review of 140 clinical journals as well as articles identified by other boards and sources and will emphasize robust randomized clinical trials, systematic reviews, and meta-analyses. Well-designed cohort and case-controlled studies will be considered for appropriate clinical questions. To promote learning, we will develop 4 multiple choice questions (MCQs) for each article; consistent with 
emphasizing mastery for our diplomates, we will require diplomates to get 100\% of the MCQs correct, providing them correct answers and rationales after their first attempt and the opportunity to retest repeatedly until successful. Questions will be designed not only to address the clinical setting and generalizability of the study but also highlight important core methodologic principles as well as the applicability of the findings to clinical practice.

Why emphasize full articles and ask MCQs? Although awareness of new evidence is an essential first step in practicing the art of evidence-based medicine, ABFM believes that the application of this knowledge to patients sitting across from them is 1 of the hallmarks of being a "personal physician." Shared decision-making depends on our ability to integrate and, if appropriate, move beyond population-based guidelines, article conclusions, or "expert" opinion to help patients devise a care plan consistent with both medical science and each patient's own preferences, goals, and values. ${ }^{10} \mathrm{We}$ believe this customization of care is best served by a physician with more granular understanding of the evidence. Like Osler's original journal club, the goal of the ABFM is to support clinical learning by doing the work of searching and prioritizing articles-and leaving the final clinical application to the personal physician.

ABFM also hopes to support the development of our specialty and profession. As headlines reveal regularly, the need for robust primary care is acute, and well-trained family physicians trained in critical thinking and staying current will play a foundational role in improving population health. Our hope is that providing this resource to our discipline will support family medicine residency journal clubs and scholarship and hasten the ongoing evolution of continuing medical education to a more evidence-based, practice-changing focus. We also look forward to working with other ABMS boards to improve the methodology of journal article-based components of our certification portfolios. A key first step will be to focus on increasing the robustness of assessments to improve learning and clinical implementation.

In conclusion, the ABFM is committed to developing a national journal club for family medicine. Working with our partner organizations, we have recruited a national committee to help develop a pilot, select the articles, write the questions and critiques, and develop an evaluation strategy.

Overall our goals are to:

1. Support family physicians in keeping current with the published, peer-reviewed literature that is relevant, methodologically strong, and practice-changing.

2. Empower family physicians to develop and implement evidence-informed practice.

3. Promote in-depth understanding and management of clinical issues by thorough reading of potentially practice-changing articles.

4. Improve the performance of family physicians in critically appraising the medical literature and translating the evidence into practice.

5. Support the development of innovative educational models by family medicine residencies, departments, the AAFP, and other partners, which are designed to help physicians stay abreast of the contemporary medical literature.

To see this article online, please go to: http://jabfm.org/content/ 33/Supplement/S24.full.

\section{References}

1. Topf JM, Sparks MA, Phelan PJ, et al. The evolution of the journal club: from Osler to Twitter. Am J Kidney Dis 2017;69:827-36.

2. Osler W. Osler's "A way of life" and other addresses, with commentary and annotations. Durham (NC): Duke University Press; 2001.

3. National Research Council. 1959. Proceedings of the International Conference on Scientific Information: Two Volumes. Washington, DC: The National Academies Press. https://doi.org/10.17226/10866.

4. Alper BS, Hand JA, Elliott SG, et al. How much effort is needed to keep up with the literature relevant for primary care? J Med Libr Assoc 2004;92:429-37.

5. Shaughnessy AF. Keeping up with the medical literature: how to set up a system. Am Fam Physician 2009;79:25-6.

6. Slawson DC, Shaughnessy AF, Bennett JH. Becoming a medical information master: feeling good about not knowing everything. J Fam Pract 1994;38:505-13.

7. Rao VM, Levin DC. The overuse of diagnostic imaging and the Choosing Wisely initiative. Ann Intern Med 2012;157:574-6.

8. Wright JT, Jr., Williamson JD, Whelton PK, et al. SPRINT Research Group. A randomized trial of intensive versus standard blood-pressure control. $\mathrm{N}$ Engl J Med 2015;373:2103-16. doi:http://dx.doi .org/10.1056/NEJMoa1511939.

9. Yudkowsky R, Park YS, Lineberry M, Knox A, Ritter EM. Setting mastery learning standards. Acad Med 2015;90:1495-500.

10. Friedberg MW, Van Busum K, Wexler R, Bowen $M$, Schneider EC. A demonstration of shared decision making in primary care highlights barriers to adoption and potential remedies. Health Aff (Millwood) 2013;32:268-75. 